\title{
Carcinogenesis-related changes in iron metabolism in chronic obstructive pulmonary disease subjects with lung cancer
}

\author{
KAMIL BRZÓSKA ${ }^{1}$, TERESA BARTŁOMIEJCZYK ${ }^{1}$, BARBARA SOCHANOWICZ ${ }^{1}$, \\ MAGDALENA CYMERMAN ${ }^{1}$, JACEK GRUDNY $^{2}$, JACEK KOŁAKOWSKI $^{3}$, MARCIN KRUSZEWSKI $^{1,4,5}$, \\ PAWEŁ ŚLIWIŃSKI ${ }^{3}$, KAZIMIERZ ROSZKOWSKI-ŚLIŻ ${ }^{2}$ and LUCYNA KAPKA-SKRZYPCZAK ${ }^{4,5}$ \\ ${ }^{1}$ Institute of Nuclear Chemistry and Technology, Centre for Radiobiology and Biological Dosimetry, 03-195 Warsaw; \\ ${ }^{2}$ Institute of Tuberculosis and Lung Diseases, Third Department of Lung Diseases; \\ ${ }^{3}$ Institute of Tuberculosis and Lung Diseases, Department of Diagnosis and Treatment of Respiratory Insufficiency, \\ 01-138 Warsaw; ${ }^{4}$ Institute of Rural Health, Department of Molecular Biology and Translational Research, 20-090 Lublin; \\ ${ }^{5}$ University of Information Technology and Management, Faculty of Medicine, Department of Medical Biology and \\ Translational Research, 35-225 Rzeszów, Poland
}

Received January 23, 2017; Accepted August 10, 2018

DOI: $10.3892 / \mathrm{ol} .2018 .9459$

\begin{abstract}
Chronic obstructive pulmonary disease (COPD) is often accompanied by lung cancer. In our previous work, it was observed that matrix metalloproteinase-3 and haptoglobin $(H P)$ polymorphisms were potential markers of enhanced susceptibility to lung cancer development among male COPD subjects. Here, results are reported on blood serum levels of several proteins involved in iron metabolism, inflammation and the oxidative stress response compared between the same groups of subjects. The blood serum levels of tumor necrosis factor $\alpha(\mathrm{TNF} \alpha)$, transferrin, hepcidin, ferritin, soluble transferrin receptor and 8-oxo-2'-deoxyguanosine were compared, as well as total iron-binding capacity (TIBC) and ceruloplasmin ferroxidase activity in two groups of subjects: Male COPD patients (54 subjects) and male COPD patients diagnosed with lung cancer (53 subjects). Statistically significant differences were identified between the two groups in transferrin and TNF $\alpha$ levels, as well as in TIBC; all three parameters were lower in the group consisting of COPD patients diagnosed with lung cancer $(\mathrm{P}<0.01)$. It was also revealed that $H P$ genotype $1 / 2$ was concomitant with low transferrin blood level in subjects with COPD; this apparent dependence was absent in the COPD + cancer subjects. The results indicate a role of iron metabolism in the susceptibility to lung cancer in COPD-affected subjects. They also emphasize the importance
\end{abstract}

Correspondence to: Dr Lucyna Kapka-Skrzypczak, Institute of Rural Health, Department of Molecular Biology and Translational Research, 2 Jaczewskiego Street, 20-090 Lublin, Poland E-mail: lucynakapka@gmail.com

Key words: chronic obstructive pulmonary disease, lung cancer, iron metabolism proteins, haptoglobin polymorphism, oxidative stress of individual capacity for an effective response to oxidative stress during the pathogenic process as $H P$ is a plasma protein that binds free hemoglobin and its polymorphism results in proteins with altered hemoglobin-binding capacity and different antioxidant and iron-recycling functions.

\section{Introduction}

The risk factors for lung cancer are usually identified by comparing the studied feature between healthy subjects and lung cancer patients. This approach has determined a series of risk factors, both genetic and epigenetic (1-7). Since the association between lung cancer and chronic obstructive pulmonary disease (COPD) has been reported in numerous studies (8-12), the risk factors that influence the morbidity of lung cancer in subjects with COPD constitute a separate problem.

A common initial pathogenic event in COPD and lung cancer is oxidative stress, caused by smoking or environmental factors. This initiates several pathways depending on genetic and epigenetic factors, which to some extent, overlap in COPD and lung cancer $(13,14)$. The common feature is initial activation of transcription factors and subsequent trans-activation of inflammation-related genes. In addition, oxidative DNA damage is inflicted, which may lead to genomic instability and the initiation of cancer, if insufficiently or incorrectly repaired (15). Thus, when searching for genetic factors that increase the risk of lung cancer in COPD subjects, it seems logical to examine polymorphisms in DNA repair genes, and in genes that code for proteins involved in inflammation and tissue remodeling, since these have been associated with COPD and cancer progression (8-12).

Previously, our group has compared the genotype distribution of single nucleotide polymorphisms (SNPs) in the genes encoding several matrix metalloproteinases (MMPs), DNA repair proteins, tumor necrosis factor $\alpha(\mathrm{TNF} \alpha)$ and haptoglobin $(H P)$ in two groups of male Caucasian subjects: The first group consisted of patients with COPD and lung cancer, 
whereas the second group consisted of patients with COPD only. It was observed that distributions of genotypes of $M M P 3$ and $H P$ polymorphisms were significantly different between the studied groups $(16,17)$. The HP gene is located on chromosome $16 \mathrm{q} 22$ and has two major alleles in humans (18). Allele 1 contains five exons whereas allele 2 has a duplication of exons 3 and 4 of allele 1 potentially resulting from unequal crossing over between two $H P 1$ alleles (18). As a result, there are three common haptoglobin phenotypes: The homodimer $H P 1 / 1$, the linear polymer $H P 1 / 2$, and the large circular polymer $H P 2 / 2$ (18). In order to search for other factors that may affect the extent of oxidative stress, the present study focused on proteins involved in iron metabolism. Iron is an established determinant of oxidative stress, being responsible for the induction of DNA damage and activation of many signaling pathways (19). Here, results are reported on blood serum levels of several proteins involved in iron metabolism, inflammation and the oxidative stress response compared between the same groups of subjects as in our previous work.

\section{Materials and methods}

Subjects. The patients were diagnosed and treated at the 2nd Department of Respiratory Medicine and 3rd Department of Respiratory Medicine and Oncology of the Institute of Tuberculosis and Lung Diseases in Warsaw, Poland from January 2007 to December 2009. The study protocol conformed to the Declaration of Helsinki, and was approved by the Institutional Ethics Committee of the Institute of Tuberculosis and Lung Diseases (Warsaw, Poland). Each participating patient had provided signed informed consent following a detailed explanation of the study protocols. The subjects were examined in two groups, selected according to gender, age, smoking habits and diagnosed disease. There were 53 male COPD patients with lung cancer and 54 male patients with COPD only. The detailed characteristics of the subject groups have been presented in our previous paper (17).

ELISA measurements. A total of $10 \mathrm{ml}$ of blood was collected from each patient into a tube containing no anticoagulant. Blood samples were incubated in an upright position for $30 \mathrm{~min}$ at room temperature to allow clotting and centrifuged in a horizontal rotor for $10 \mathrm{~min}$ at $1,500 \mathrm{x} \mathrm{g}$ at room temperature. Serum was transferred to sterile eppendorf tubes and stored at $-70^{\circ} \mathrm{C}$ in $0.5 \mathrm{ml}$ aliquots. ELISA kits for the following proteins were used according to the manufacturer's instructions: Ferritin (Alpha Diagnostic International, San Antonio, TX, USA, Catalog no. 1810); hepcidin prohormone (DRG Instruments GmbH, Marburg, Germany; catalog no. EIA-4644); soluble transferrin receptor (sTfR) (BioVendor, Brno, Czech Republic; catalog no. RD194011100, TNFa and transferrin (Assaypro St. Charles, MO, USA; catalog no. ET2010-1 and ET3105-1, respectively); and 8-oxo-2'-deoxyguanosine (HT (High throughput) 8-oxo-dG ELISA kit; R\&D Systems, Inc., Minneapolis, MN, USA; catalog no. 4380-096-K). Thawed serum was not reused for testing. Each ELISA test included a standard curve, the shape of which had been compared with the data provided by the manufacturer as well as a positive control (sample with known antigen concentration) and negative control (sample containing no antigen). All samples and standards were run in triplicate and coefficients of variation were compared with the data provided by the manufacturer.

Total iron-binding capacity. TIBC values of serum were determined using the Randox TIBC colorimetric assay (Randox Laboratories Ltd., Crumlin, UK) according to the manufacturer's recommendations. A total of $0.5 \mathrm{ml}$ of serum from each subject was used for the measurement.

Ceruloplasmin ferroxidase activity (CFA). The CFA of serum samples was measured according to the method described by Erel (20). The chromogen, (3-(2-pyridyl)-5,6-bis(2-[5-furylsulfonic acid])-1,2,4-triazine), forms a coloured complex with ferrous ions, but not with ferric ions. The difference in the ferrous ion concentration prior to and following the enzymatic reaction indicates the quantity of the oxidized ferrous ion. The quantity of enzyme that converted $1 \mu \mathrm{mol}$ of substrate into product per minute was defined as 1 unit.

Statistical analysis. Data are presented as the mean with standard error of the mean and/or standard deviation as indicated. Differences between the studied groups in blood levels of proteins and 8-oxodG as well as in TIBC and CFA were analysed by Mann-Whitney U-tests. Analysis of transferrin blood level between groups with different $H P$ genotypes determined previously (17) was performed using one-way analysis of variance (ANOVA) followed by post-hoc Tukey's tests. To estimate correlations between the parameters under study, Pearson's correlation coefficients (r) were computed. In all tests, significance was accepted at $\mathrm{P}<0.05$. All statistical analyses were performed using Statistica 7 software (StatSoft, Inc., Tulsa, OK, USA).

\section{Results}

Comparison of oxidative stress, iron metabolism, and inflammation markers between COPD patients with and without lung cancer. The blood serum levels of the oxidative stress marker, 8-oxodG, and several proteins involved in iron metabolism and inflammation were analyzed in two groups of patients: The first group consisted of patients with COPD and lung cancer, whereas the second group consisted of patients with COPD only.

The blood serum level of TNFa was lower in the COPD + cancer group compared with in the COPD group $(\mathrm{P}<0.01$; Fig. 1A). Additionally, the difference in transferrin level was significant, and its level was lower in the COPD + cancer subjects $(\mathrm{P}<0.01$; Fig. $1 \mathrm{~B})$. No statistically significant differences were observed in the blood serum levels of other proteins involved in iron metabolism (hepcidin, ferritin and sTfR) (Fig. 2) or 8-oxodG (Fig. 3).

Furthermore, TIBC and CFA were compared (Fig. 4). The lower TIBC index in COPD + cancer subjects was statistically significantly different to that of the COPD group $(\mathrm{P}<0.01)$.

Correlation analysis. Table I sumarizes the analysis of correlations between measured parameters. Notable differences between the groups under study were observed. Namely, in COPD-only patients, hepcidin level was positively correlated 

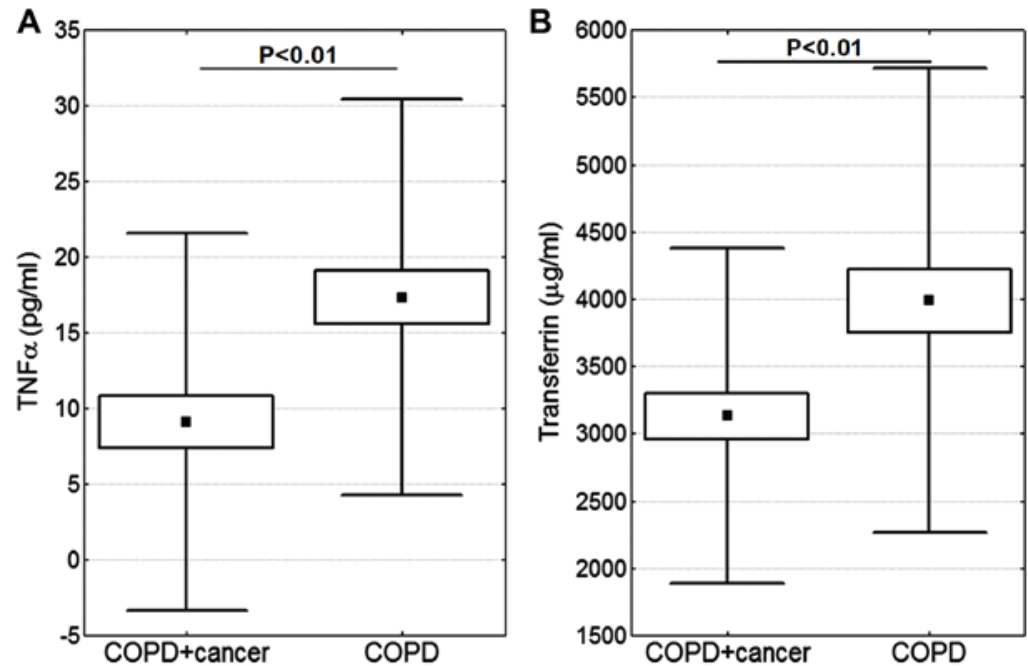

Figure 1. Box plots of mean levels of (A) TNF $\alpha$ and (B) transferrin in the serum of subjects with COPD or COPD and lung cancer. In the box plots, the middle square represents the mean, the boxes standard error of the mean and the whiskers standard deviation. Differences between groups determined as statistically significant in the Mann-Whitney U-test are indicated. TNF $\alpha$, tumor necrosis factor $\alpha$; COPD, chronic obstructive pulmonary disease.
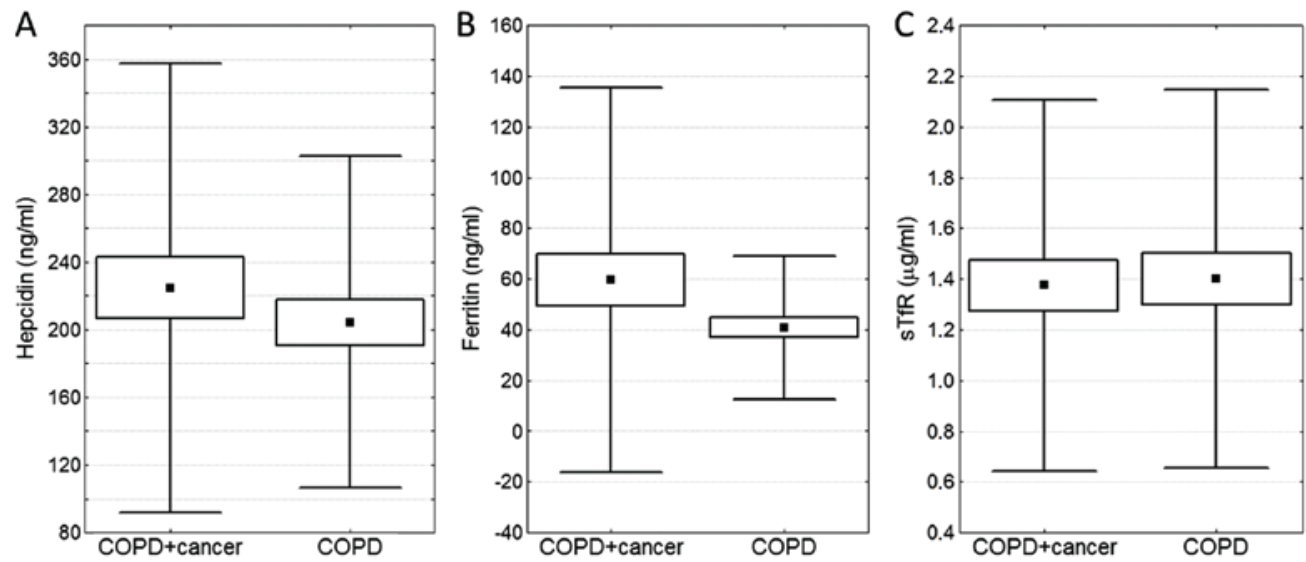

Figure 2. Box plots of mean levels of proteins involved in iron metabolism: (A) Hepcidin, (B) ferritin and (C) sTfR, in the serum of subjects with COPD or COPD and lung cancer. In the box plots, the middle square represents the mean, the boxes standard error of the mean and the whiskers standard deviation. All differences were not significant in the Mann-Whitney U-test ( $P>0.05)$. sTfR, soluble transferrin receptor; COPD, chronic obstructive pulmonary disease.

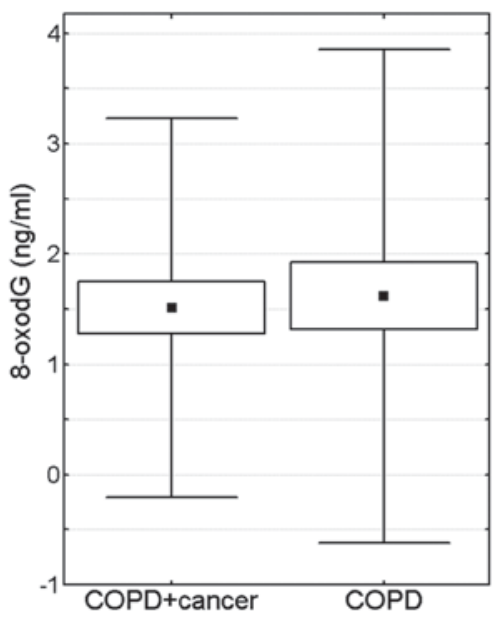

Figure 3. Box plots of mean levels of 8 -oxodG in the serum of subjects with COPD or COPD and lung cancer. In the box plots, the middle square represents the mean, the boxes standard error of the mean and the whiskers standard deviation. Difference between the groups was not significant in the Mann-Whitney U-test ( $\mathrm{P}>0.05)$. 8-oxodG, 8-oxo-2'-deoxyguanosine; COPD, chronic obstructive pulmonary disease. with CFA and 8-oxodG level ( $\mathrm{r}=0.31$ and $0.60 ; \mathrm{P}<0.05$ ); whereas in patients with COPD and lung cancer, hepcidin level also showed positive correlation with ferritin level $(\mathrm{r}=0.45$; $\mathrm{P}<0.05)$, as well as negative correlation with transferrin level and TIBC ( $\mathrm{r}=-0.27$ and $-0.29 ; \mathrm{P}<0.05)$. In the case of ferritin level, in COPD-only patients it was negatively correlated with tranferrin level and TIBC ( $\mathrm{r}=-0.33$ and $-0.40 ; \mathrm{P}<0.05)$, and positively correlated with 8-oxodG level $(\mathrm{r}=0.39 ; \mathrm{P}<0.05)$; whereas in patients with COPD and lung cancer, ferritin level was not correlated with the levels of transferrin or 8-oxodG, but instead correlation with hepcidin and CFA ( $r=0.45$ and $0.29 ; \mathrm{P}<0.05)$ was observed.

Impact of HP polymorphism on iron metabolism, and inflammation markers. The influence of $H P$ polymorphism on TIBC, as well as on the blood serum levels of TNFa and transferrin was examined. From one-way ANOVA, it was determined that $H P$ genotype $1 / 2$ was concomitant with a low transferrin blood level in the subjects with COPD only (Fig. 5A), but not in the subjects with COPD and lung cancer (Fig. 5B). 
Table I. Pearson's correlation coefficients (r) for correlations between the measured parameters in COPD and COPD + lung cancer subjects.

A, All subjects $(n=107)$

\begin{tabular}{lccccccc}
\hline & TNF $\alpha$ & sTfR & Ferritin & Transferrin & TIBC & CFA & Hepcidin \\
\hline TNF $\alpha$ & 1.00 & - & - & - & - & - & - \\
sTfR & -0.09 & 1.00 & - & - & - & - & - \\
Ferritin & -0.08 & 0.03 & 1.00 & - & - & - & - \\
Transferrin & $\mathbf{0 . 4 7}$ & 0.02 & $\mathbf{- 0 . 2 6}$ & 1.00 & - & - & - \\
TIBC & $\mathbf{0 . 2 1}$ & 0.13 & $\mathbf{- 0 . 3 4}$ & $\mathbf{0 . 4 2}$ & 1.00 & - & - \\
CFA & 0.11 & 0.17 & $\mathbf{0 . 2 6}$ & -0.06 & -0.05 & 1.00 & - \\
Hepcidin & -0.11 & 0.13 & $\mathbf{0 . 3 8}$ & $\mathbf{- 0 . 2 4}$ & -0.11 & $\mathbf{0 . 3 5}$ & 1.00 \\
8-oxodG & -0.18 & 0.08 & 0.18 & $\mathbf{- 0 . 3 1}$ & -0.11 & $\mathbf{0 . 2 9}$ & $\mathbf{0 . 5 1}$ \\
\hline
\end{tabular}

B, COPD-only subjects $(n=54)$

\begin{tabular}{|c|c|c|c|c|c|c|c|c|}
\hline & TNF $\alpha$ & sTfR & Ferritin & Transferrin & TIBC & CFA & Hepcidin & 8-oxodG \\
\hline $\mathrm{TNF} \alpha$ & 1.00 & - & - & - & - & - & - & - \\
\hline sTfR & -0.05 & 1.00 & - & - & - & - & - & - \\
\hline Ferritin & -0.05 & -0.07 & 1.00 & - & - & - & - & - \\
\hline Transferrin & 0.40 & 0.03 & -0.33 & 1.00 & - & - & - & - \\
\hline TIBC & 0.01 & 0.22 & -0.40 & 0.30 & 1.00 & - & - & - \\
\hline CFA & 0.02 & 0.14 & 0.24 & -0.18 & 0.02 & 1.00 & - & - \\
\hline Hepcidin & -0.15 & 0.24 & 0.17 & -0.19 & 0.13 & 0.31 & 1.00 & - \\
\hline 8-oxodG & -0.23 & 0.09 & 0.39 & -0.32 & -0.07 & 0.48 & 0.60 & 1.00 \\
\hline
\end{tabular}

C, COPD + lung cancer subjects $(n=53)$

\begin{tabular}{|c|c|c|c|c|c|c|c|c|}
\hline & $\mathrm{TNF} \alpha$ & sTfR & Ferritin & Transferrin & TIBC & CFA & Hepcidin & 8-oxodG \\
\hline $\mathrm{TNF} \alpha$ & 1.00 & - & - & - & - & - & - & - \\
\hline sTfR & -0.17 & 1.00 & - & - & - & - & - & - \\
\hline Ferritin & -0.04 & 0.08 & 1.00 & - & - & - & - & - \\
\hline Transferrin & 0.46 & -0.02 & -0.24 & 1.00 & - & - & - & - \\
\hline TIBC & 0.23 & 0.03 & -0.33 & 0.44 & 1.00 & - & - & - \\
\hline CFA & 0.18 & 0.20 & 0.29 & 0.08 & -0.15 & 1.00 & - & - \\
\hline Hepcidin & -0.05 & 0.05 & 0.45 & -0.27 & -0.29 & 0.38 & 1.00 & - \\
\hline 8-oxodG & -0.15 & 0.07 & 0.15 & -0.33 & -0.25 & 0.08 & 0.48 & 1.00 \\
\hline
\end{tabular}

Correlation coefficients significant at $\mathrm{P}<0.05$ are emboldened. TNF $\alpha$, tumor necrosis factor $\alpha$; sTfR, soluble transferrin receptor; TIBC, total iron-binding capacity; CFA, ceruloplasmin ferroxidase activity; 8-oxodG, 8-oxo-2'-deoxyguanosine; COPD, chronic obstructive pulmonary disease.

\section{Discussion}

The oxidant and noxious stress responses that occur in the lungs of cigarette smokers cause damage to epithelial cells, leading to their apoptosis and the development of emphysema, as a main characteristic of COPD (21). In addition, reactive oxygen species are genotoxic agents and their interaction with DNA results in the formation of oxidized DNA bases, DNA strand breaks and chromosomal damage (22). These lesions, if unrepaired or misrepaired, may lead to cell death or genomic instability and, consequently, result in a number of diseases, including those associated with neoplastic changes $(23,24)$.

There are several reports of increased lung cancer risk being associated with polymorphisms in the DNA repair genes (25-29). Nevertheless, an analysis of pooled data from 14 studies on the significance of polymorphisms in the DNA repair genes for cancer risk, published in 2008 by the International Lung Cancer Consortium (30), indicated that mostly weak associations could be found for single polymorphisms. It should be stressed that all these analyses (25-30) were performed by 

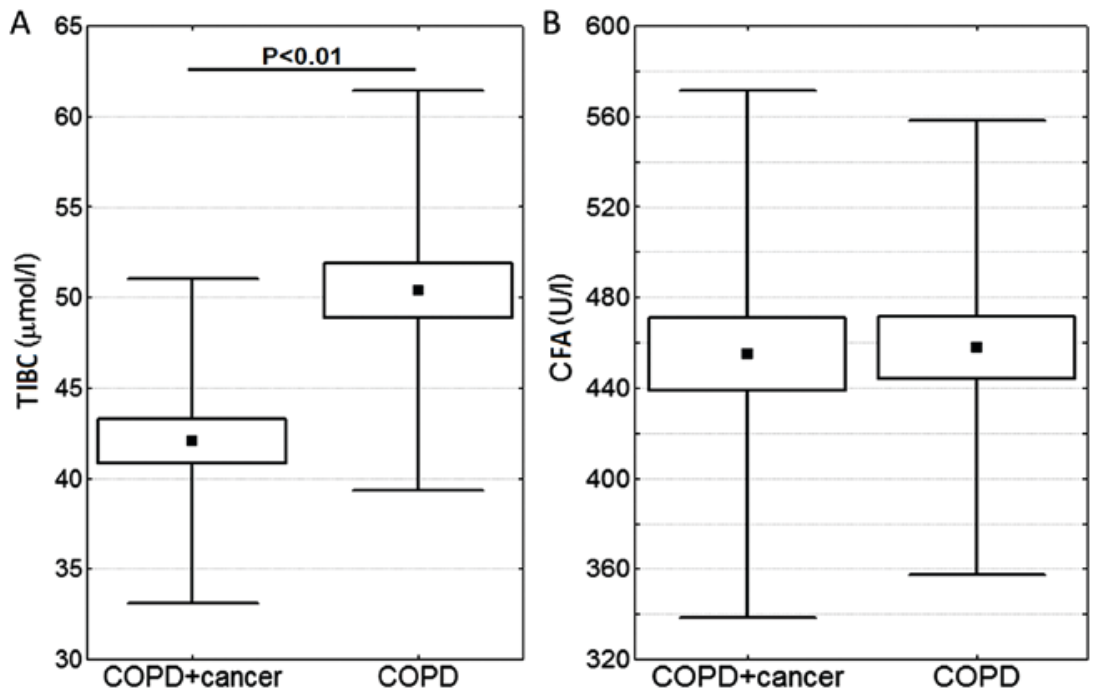

Figure 4. (A) TIBC and (B) CFA in the serum of subjects with COPD or COPD and lung cancer. In the box plots, the middle square represents the mean, the boxes standard error of the mean and the whiskers standard deviation. The difference in TIBC was statistically significant in the Mann-Whitney U-test. TIBC, total iron-binding capacity; CFA, ceruloplasmin ferroxidase activity; COPD, chronic obstructive pulmonary disease.
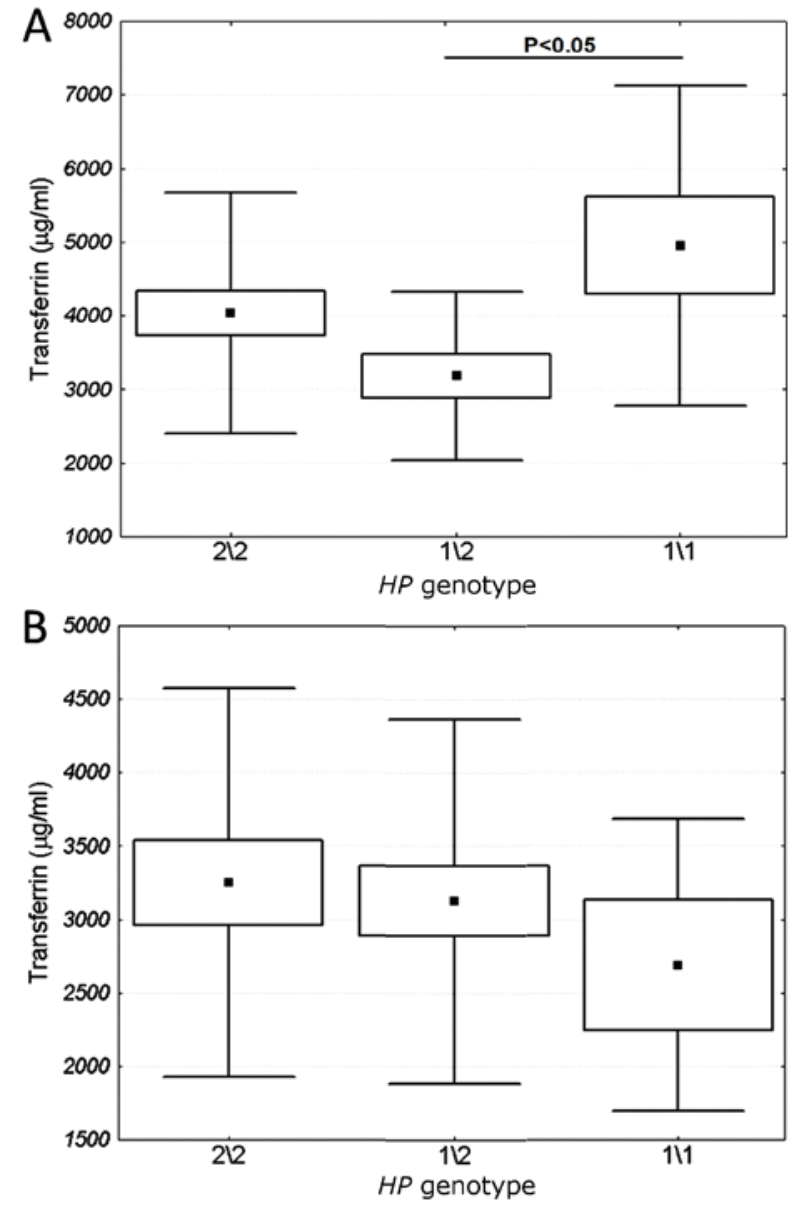

Figure 5. (A) $H P$ genotype $1 / 2$ was concomitant with the low blood transferrin level in subjects with COPD. (B) This dependence was absent in the subjects with COPD and lung cancer. The marked difference was significant in one-way analysis of variance followed by post-hoc Tukey's test.

comparing healthy subjects with those with lung cancer. In our previous work, COPD patients were compared with patients with both COPD and lung cancer. No significant differences in the distribution of polymorphisms in DNA repair genes were identified between the two groups. Similarly, the frequency of polymorphisms in the tumor protein p53 and cyclin dependent kinase inhibitor 1 genes did not differ between COPD and COPD + cancer subjects (17). This result is consistent with the similar blood level of 8-oxodG, a marker of oxidative DNA damage, in the same two groups of subjects, as reported in the present study.

During a previous study on the same groups of subjects, no statistically significant difference was found in the frequency of SNPs in the gene encoding TNF $\alpha$. By contrast, a significant difference between the compared groups was identified in the distribution of genotypes of the HP gene (17). HP belongs to the acute phase proteins that are present in serum; their increase and altered glycosylation accompany inflammation and tumorigenesis (31). The biological function of $H P$ is to bind free hemoglobin in blood, thus preventing iron loss and allowing the recycling of heme iron in the reticuloendothelial system in the liver (32-34). Therefore, acting as a hemoglobin scavenger, $H P$ lowers iron concentration, and facilitates the anti-inflammatory response (34). Among the known $H P$ phenotypes, $H P 1 / 1$ is the most effective in binding free hemoglobin, thus suppressing the oxidative stress and inflammatory response associated with free hemoglobin. $H P 2 / 2$ is the least effective, whereas $H P 1 / 2$ has an intermediate anti-oxidative activity (35-37).

The formation of reactive oxygen radicals frequently occurs in Haber-Weiss and Fenton-type reactions with the participation of ferrous ions $\left(\mathrm{Fe}^{2+}\right)$, therefore, homeostasis disorders of this element may be important in the development of cancer (19). In fact, such has been observed in patients with various cancers: Iron was identified as a potential carcinogen approximately 25 years ago (38-41) also in lung cancer (42). Recent reviews $(43,44)$ summarize the research on iron metabolism in the cancer cell and the possible applications of iron targeted therapy. In the present study, it was revealed that $H P 1 / 2$ genotype was associated with low transferrin blood level in patients with COPD. This relationship was absent in 
patients with COPD and lung cancer, likely reflecting carcinogenesis-related changes in iron metabolism. Such changes were also manifested in the significantly lower blood levels of $\mathrm{TNF} \alpha$, transferrin and TIBC in the patients with COPD and lung cancer.

In conclusion, the results of the present study indicate the importance of iron metabolism in the development and progression of lung cancer in COPD-affected subjects. In future studies by our group, the aim will be to further investigate the mechanisms of COPD and lung cancer development and the relationship between these two diseases, with focus on the roles of the immune system, iron metabolism and the oxidative stress response in their pathogenesis. Specifically, analysis of the expression of genes related to these processes is intended on the transcriptomic level, in circulating immune cells isolated from COPD and lung cancer patients as well as from tumor samples. Further aims will be to verify if epigenetic factors including microRNA expression and DNA methylation may be responsible for the effects observed in the present study (for example, the association between transferrin level and haptoglobin genotype), and to investigate their role in COPD and lung cancer pathogenesis.

\section{Acknowledgements}

The authors thank Professor Irena Szumiel (Institute of Nuclear Chemistry and Technology, Centre for Radiobiology and Biological Dosimetry, Warsaw, Poland; Retired) for her advice and assistance in writing the manuscript.

\section{Funding}

The present study was supported by the Ministry of Science and Higher Education, Warsaw, Poland (grant no. N402 109 32/3503).

\section{Availability of data and materials}

The datasets used and/or analysed during the current study are available from the corresponding author on reasonable request.

\section{Authors' contributions}

MK, PŚ, KRŚ and LKS designed the study. KB, TB, BS, MC, JG and JK collected the data. KB, PŚ, KRŚ and LKS analysed the data. KB and MK performed statistical analysis. KB and LKS wrote the manuscript. All authors read and approved the final manuscript.

\section{Ethics approval and consent to participate}

The study protocol conformed to the Declaration of Helsinki, and was approved by the Institutional Ethics Committee of the Institute of Tuberculosis and Lung Diseases (Warsaw, Poland). Each participating patient had provided signed informed consent following a detailed explanation of the study protocols.

\section{Patient consent for publication}

Study participants provided their consent for the publication of this data and any associated images.

\section{Competing interests}

The authors declare that they have no competing interests.

\section{References}

1. Coussens LM and Werb Z: Inflammation and cancer. Nature 420: 860-867, 2002.

2. Dik S, Scheepers PT and Godderis L: Effects of environmental stressors on histone modifications and their relevance to carcinogenesis: A systematic review. Crit Rev Toxicol 42: 491-500, 2012.

3. Edwards TM and Myers JP: Environmental exposures and gene regulation in disease etiology. Environ Health Perspect 115: 1264-1270, 2007.

4. Hursting SD and Berger NA: Energy balance, host-related factors, and cancer progression. J Clin Oncol 28: 4058-4065, 2010.

5. Hursting SD and Hursting MJ: Growth signals, inflammation, and vascular perturbations: Mechanistic links between obesity, metabolic syndrome, and cancer. Arterioscler Thromb Vasc Biol 32: 1766-1770, 2012.

6. Maynard S, Schurman SH, Harboe C, de Souza-Pinto NC and Bohr VA: Base excision repair of oxidative DNA damage and association with cancer and aging. Carcinogenesis 30: 2-10, 2009.

7. Weidman JR, Dolinoy DC, Murphy SK and Jirtle RL: Cancer susceptibility: Epigenetic manifestation of environmental exposures. Cancer J 13: 9-16, 2007.

8. Adcock IM, Caramori G and Barnes PJ: Chronic obstructive pulmonary disease and lung cancer: New molecular insights. Respiration 81: 265-284, 2011.

9. Decramer M, Janssens W and Miravitlles M: Chronic obstructive pulmonary disease. Lancet 379: 1341-1351, 2012.

10. Decramer M, Rennard S, Troosters T, Mapel DW, Giardino N, Mannino D, Wouters E, Sethi S and Cooper CB: COPD as a lung disease with systemic consequences-clinical impact, mechanisms, and potential for early intervention. COPD 5: 235-256, 2008.

11. Yang IA, Relan V, Wright CM, Davidson MR, Sriram KB, Savarimuthu Francis SM, Clarke BE, Duhig EE, Bowman RV and Fong KM: Common pathogenic mechanisms and pathways in the development of COPD and lung cancer. Expert Opin Ther Targets 15: 439-456, 2011.

12. Young RP and Hopkins RJ: How the genetics of lung cancer may overlap with COPD. Respirology 16: 1047-1055, 2011.

13. Bozinovski S, Vlahos R, Anthony D, McQualter J, Anderson G, Irving L and Steinfort D: COPD and squamous cell lung cancer: Aberrant inflammation and immunity is the common link. $\mathrm{Br}$ J Pharmacol 173: 635-648, 2016.

14. Durham AL and Adcock IM: The relationship between COPD and lung cancer. Lung Cancer 90: 121-127, 2015.

15. Aoshiba K, Zhou F, Tsuji T and Nagai A: DNA damage as a molecular link in the pathogenesis of COPD in smokers. Eur Respir J 39: 1368-1376, 2012.

16. Brzóska K, Bartlomiejczyk T, Sochanowicz B, Cymerman M, Grudny J, Kołakowski J, Kapka-Skrzypczak L, Kruszewski M, Sliwiński P and Roszkowski-Śliż K: Matrix metalloproteinase 3 polymorphisms as a potential marker of enhanced susceptibility to lung cancer in chronic obstructive pulmonary disease subjects. Ann Agric Environ Med 21: 546-551, 2014.

17. Grudny J, Kolakowski J, Kruszewski M, Szopiński J, Sliwiński P, Wiatr E, Winek J, Załęska J, Zych J and Roszkowski-Śliż K: Association of genetic dependences between lung cancer and chronic obstructive pulmonary disease. Pneumonol Alergol Pol 81: 308-318, 2013.

18. Goldenstein H, Levy NS and Levy AP: Haptoglobin genotype and its role in determining heme-iron mediated vascular disease. Pharmacol Res 66: 1-6, 2012.

19. Kruszewski M: Labile iron pool: The main determinant of cellular response to oxidative stress. Mutat Res 531: 81-92, 2003.

20. Erel O: Automated measurement of serum ferroxidase activity. Clin Chem 44: 2313-2319, 1998.

21. Boukhenouna S, Wilson MA, Bahmed K and Kosmider B: Reactive oxygen species in chronic obstructive pulmonary disease. Oxid Med Cell Longev 2018: 5730395, 2018.

22. Markkanen E: Not breathing is not an option: How to deal with oxidative DNA damage. DNA Repair (Amst) 59: 82-105, 2017.

23. Lewandowska $H$, Kalinowska M, Lewandowski W, Stepkowski TM and Brzóska K: The role of natural polyphenols in cell signaling and cytoprotection against cancer development. J Nutr Biochem 32: 1-19, 2016. 
24. Liguori I, Russo G, Curcio F, Bulli G, Aran L, Della-Morte D, Gargiulo G, Testa G, Cacciatore F, Bonaduce D and Abete P. Oxidative stress, aging, and diseases. Clin Interv Aging 13: 757-772, 2018

25. Hung RJ, Hall J, Brennan P and Boffetta P: Genetic polymorphisms in the base excision repair pathway and cancer risk: A HuGE review. Am J Epidemiol 162: 925-942, 2005.

26. López-Cima MF, Gonzalez-Arriaga P, Garcia-Castro L, Pascual T, Marrón MG, Puente XS and Tardón A: Polymorphisms in XPC, XPD, XRCC1, and XRCC3 DNA repair genes and lung cancer risk in a population of northern Spain. BMC Cancer 7: $162,2007$.

27. Manuguerra M, Saletta F, Karagas MR, Berwick M, Veglia F, Vineis P and Matullo G: XRCC3 and XPD/ERCC2 single nucleotide polymorphisms and the risk of cancer: A HuGE review. Am J Epidemiol 164: 297-302, 2006.

28. Park JY, Lee SY, Jeon HS, Bae NC, Chae SC, Joo S, Kim CH, Park JH, Kam S, Kim IS and Jung TH: Polymorphism of the DNA repair gene XRCC1 and risk of primary lung cancer. Cancer Epidemiol Biomarkers Prev 11: 23-27, 2002.

29. Zhou W, Liu G, Miller DP, Thurston SW, Xu LL, Wain JC, Lynch TJ, Su L and Christiani DC: Polymorphisms in the DNA repair genes XRCC1 and ERCC2, smoking, and lung cancer risk. Cancer Epidemiol Biomarkers Prev 12: 359-365, 2003.

30. Hung RJ, Christiani DC, Risch A, Popanda O, Haugen A, Zienolddiny S, Benhamou S, Bouchardy C, Lan Q, Spitz MR, et al: International lung cancer consortium: Pooled analysis of sequence variants in DNA repair and cell cycle pathways. Cancer Epidemiol Biomarkers Prev 17: 3081-3089, 2008.

31. Dempsey E and Rudd PM: Acute phase glycoproteins: Bystanders or participants in carcinogenesis? Ann N Y Acad Sci 1253: 122-132, 2012.

32. Delanghe JR and Langlois MR: Haptoglobin polymorphism and body iron stores. Clin Chem Lab Med 40: 212-216, 2002.

33. Dobryszycka W: Biological functions of haptoglobin-new pieces to an old puzzle. Eur J Clin Chem Clin Biochem 35: 647-654, 1997.
34. Nielsen MJ and Moestrup SK: Receptor targeting of hemoglobin mediated by the haptoglobins: Roles beyond heme scavenging. Blood 114: 764-771, 2009.

35. Levy AP, Asleh R, Blum S, Levy NS, Miller-Lotan R, Kalet-Litman S, Anbinder Y, Lache O, Nakhoul FM, Asaf R, et al: Haptoglobin: Basic and clinical aspects. Antioxid Redox Signal 12: 293-304, 2010.

36. Sadrzadeh SM and Bozorgmehr J: Haptoglobin phenotypes in health and disorders. Am J Clin Pathol 121 (Suppl): S97-S104, 2004.

37. Wassell J: Haptoglobin: Function and polymorphism. Clin Lab 46: 547-552, 2000.

38. Huang X: Iron overload and its association with cancer risk in humans: Evidence for iron as a carcinogenic metal. Mutat Res 533: 153-171, 2003.

39. Knekt P, Reunanen A, Takkunen H, Aromaa A, Heliövaara M and Hakulinen T: Body iron stores and risk of cancer. Int J Cancer 56: 379-382, 1994.

40. Selby JV and Friedman GD: Epidemiologic evidence of an association between body iron stores and risk of cancer. Int J Cancer 41: 677-682, 1988.

41. Toyokuni $\mathrm{S}$ and Sagripanti JL: Association between 8-hydroxy-2'-deoxyguanosine formation and DNA strand breaks mediated by copper and iron. Free Radic Biol Med 20: 859-864, 1996.

42. Zhou W, Park S, Liu G, Miller DP, Wang LI, Pothier L, Wain JC, Lynch TJ, Giovannucci E and Christiani DC: Dietary iron, zinc, and calcium and the risk of lung cancer. Epidemiology 16: 772-779, 2005

43. Richardson DR, Kalinowski DS, Lau S, Jansson PJ and Lovejoy DB: Cancer cell iron metabolism and the development of potent iron chelators as anti-tumour agents. Biochim Biophys Acta 1790: 702-717, 2009.

44. Wang SJ, Gao C and Chen BA: Advancement of the study on iron metabolism and regulation in tumor cells. Chin J Cancer 29: 451-455, 2010. 